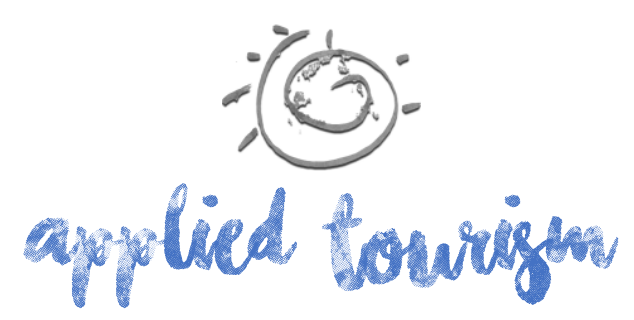

Volume 2, número 3, 2017, p. 01-25

\title{
A GASTRONOMIA E AS INDICAÇÕES GEOGRÁFICAS COMO FERRAMENTA DE VALORIZAÇÃO DO TERRITÓRIO
}

\author{
Camila Bizinelli \\ Mestre em Geografia, Universidade Federal do Paraná \\ Sócia-Proprietária do empreendimento Adocica Doceria Retrô \\ ca_bizinelli@hotmail.com
}

Franciele Cristina Manosso

Mestre em Geografia, Universidade Federal do Paraná Professora Substituta do Departamento de Turismo, da Universidade Federal do Paraná francimanosso@gmail.com

Recebido: 28 de junho, 2017

Aprovado: 27 de outubro, 2017

\section{RESUMO}

Cidades, estados e até mesmo regiões vêm se destacando na comercialização e produção de seus produtos e serviços, sendo que a qualidade e a tradição destes estão sendo atribuídas a sua origem. Neste contexto, surgem as Indicações Geográficas (IG), concedidas pelo Instituto Nacional de Propriedade Industrial - INPI. Tais são trabalhadas como um fator relevante para a proteção, bem como, para a diferenciação dos produtos ou serviços de uma determinada localidade. Neste sentido, o presente artigo tem como objetivo analisar de que forma as indicações geográficas estão sendo utilizadas para o fortalecimento da divulgação dos territórios, desde uma perspectiva gastronômica. Para tal, a metodologia de pesquisa baseou-se em pesquisa bibliográfica e documental, tendo como foco central os websites governamentais. Ao que se refere aos resultados da pesquisa, pode-se verificar que um número relevante de indicações geográficas não está sendo divulgado nos sites pertencentes aos municípios, estados e secretarias de turismo correspondentes; sendo assim, destaca-se que o número de sites próprios e presença nas redes sociais são mais significativos.

Palavras-chaves: Indicação Geográfica. Produto Local. Gastronomia. Marketing. 


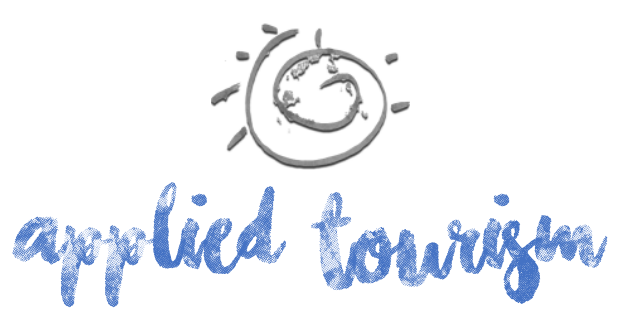

Volume 2, número 3, 2017, p. 01-25

websites próprios para a sua divulgação. Ao que diz respeito, à fundamentação teórica da presente pesquisa buscou-se contemplar os conceitos de terroir e a importância das indicações geográficas para a valorização e divulgação dos territórios, desde uma perspectiva gastronômica.

\section{REFERENCIAL TEÓRICO}

\section{Produtos Locais \& Terroir: Aproximando Conceitos}

A globalização, no âmbito da atividade turística, debate contextos diferentes ao que diz respeito ao local, que deu vida a produtos com identidade cultural, aspectos geográficos e históricos, enfatizados para agregar valores a nichos mercadológicos, tais quais: o enoturismo e o turismo gastronômico. Em tal conjuntura, enfatiza-se a identificação geográfica considerada o principal elemento que confere o diferencial para o turismo, pois os produtos e serviços são melhorados a partir da agregação de valores e credibilidade (Costa, 2014).

Nos últimos anos, observou-se um crescente aumento pela busca de produtos autóctones e/ou 'locais', que valorizem as características regionais, os quais contemplam uma 'alma', uma identidade peculiar, uma dimensão globalizante e, recentemente, uma viabilidade econômico-produtiva (Manzini, Meroni e Krucken, 2006; Silveira, 2009). De tal modo, a produção local deve ser debatida, intrinsecamente, no contexto do modo de vida da localidade a qual está inserida, dinamizando a economia (Ilbery \& Maye, 2005).

Por conseguinte, cabe salientar que estes produtos denominados de 'locais', se caracterizam por serem manifestações culturais eminentemente interligadas ao território e à comunidade que os originou, utilizando-se de recursos da biodiversidade, e, também, de modos, costumes e hábitos tradicionais de produzir (Krucken, 2009). Nesta conjuntura, devem-se incorporar recursos específicos oriundos das localidades que produzem os produtos em 


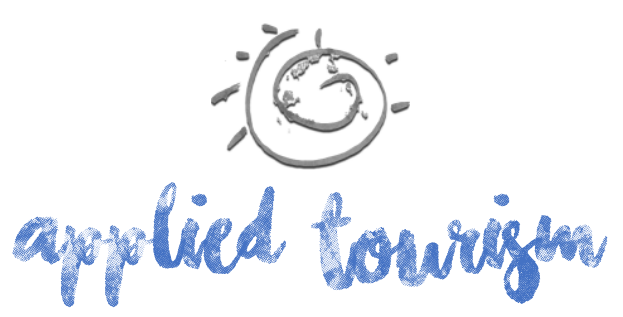

Volume 2, número 3, 2017, p. 01-25

questão, para que os mesmos se tornem competitivos gerando, desse modo, uma vantagem coletiva para o território/localidade no qual o produto está inserido (Gehlen \& Riella, 2004).

A partir das concepções de 'produtos locais' apresentados, destaca-se que o referido conceito pode-se aproximar da premissa francesa, conhecida por terroir. Bérard e Marchenay (2004) descrevem o terroir como um processo dinâmico que ajuda na representação da ligação entre tempo, seres humanos e espaço. Sendo que tal preceito pode, ainda, ser debatido como uma relação entre a origem (geografia e clima), cultura (tempo e tradução) e 'saber-fazer' (know-how), onde o 'saber-fazer' pode ser visto a partir de uma perspectiva diacrônica, que abrange tanto conhecimentos antigos quanto novos (Aurier, Fort \& Sirieix, 2005; Dekhili, Sirieix \& Cohen, 2011).

Consequentemente, pode-se inferir que ao terroir confere-se status de espaço geográfico complexo e polissêmico, pois são abrangidas as seguintes perspectivas: a) um território com suas condições de solo e clima peculiares; b) um ambiente de conhecimento e práticas; c) um conjunto de tradições e costumes localizados (Barjolle, Boisseau \& Dufour, 1998). A Figura 01 apresenta, de maneira resumida, as dimensões do terroir, que contemplam a seguinte conjuntura: dimensão agronômica e pedo-climáticas (de solo e clima), humana, técnica, cultural e simbólica, histórica. 


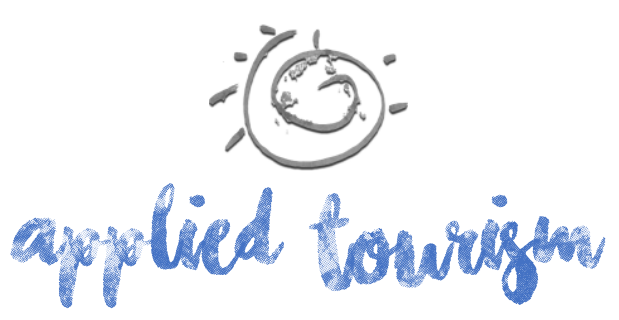

Volume 2, número 3, 2017, p. 01-25

\section{Indicações Geográficas: Agregando Valor e Credibilidade aos Produtos e Territórios.}

A mundialização, as inseguranças relacionadas à origem dos alimentos e as recorrentes crises alimentares, se de certo modo levam à padronização da produção e consumo, em contraponto, trazem, também, ambições por produtos individualizados, cuja qualidade e procedência possam ser afiançadas. Tal procura pela origem, fomenta o estabelecimento de mecanismos para valorização e garantia de qualidade diferenciada para os produtos, referenciando fatores geográficos ou tradicionais, com o desígnio de tornar peculiar a produção local, agregando valor e posicionando-a em nichos exclusivos de mercado (Vargas, 2008; Bérard \& Marchenay, 2007). Por conseguinte, Rodeghero, Müller e Bruch (p. 196, 2015) ponderam que:

Diferenciar um bem (compreendido neste um produto ou serviço) significa demonstrar no mercado, especialmente para o consumidor, que um bem é diferente de outro de mesma quantidade e espécie em face de sua origem, de suas características ou de sua qualidade. A indicação da origem comercial serve para que o consumidor saiba quem é o seu fornecedor, garantindo a sua procedência em termos comerciais.

Em tal contexto, a qualidade de um produto, inserido no cenário das Indicações Geográficas, deve ser ponderada de maneira abrangente, levando em consideração o território, os recursos empregados e a comunidade produtora (Barjolle et al, 1998; Krucken, 2001; Nicolas \& Valceschini, 1993; Tibério, Cristóvão \& Fragata, 2001). Conforme apresenta a Figura 02 . 


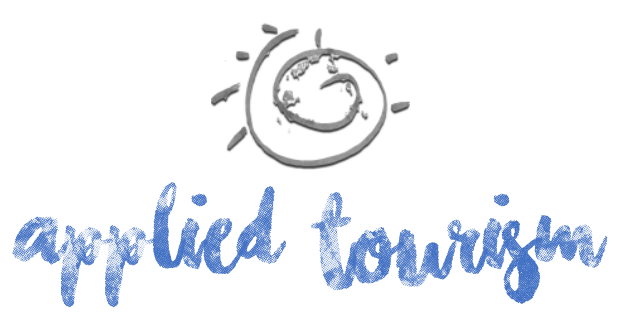

Volume 2, número 3, 2017, p. 01-25

indicação de comércio solidário; indicação de produtos da agricultura familiar; dentre outras) (Krucken, 2009).

Consequentemente, ao longo do tempo, desde que produtores, comerciantes e consumidores passaram a verificar que certos produtos, advindos de locais específicos, apresentavam qualidades exclusivas, imputáveis à sua localização geográfica, passaram a denominá-los a partir do nome geográfico de procedência - como o queijo Roquefort e os vinhos de Bordeaux (Valente, Perez, Ramos \& Chaves, 2012). Assim, surgiram as chamadas Indicações Geográficas (IG).

Este conceito, segundo o que afirma Krucken (2009), diz respeito aos referimentos geográficos empregados no desígnio de produtos agrícolas e alimentícios, que apresentam uma ou mais qualidades ligadas ao local onde são produzidos. Vargas (2008) destaca que as Indicações Geográficas podem ser divididas em: Indicação de Procedência e Denominação de Origem. Sendo classificadas, pelo 'Guia Básico - Indicação Geográfica’ (Inpi, 2017), da seguinte maneira:

- Denominação de Origem: refere-se ao nome do local, que passou a indicar produtos ou serviços, cujas qualidades ou atributos podem ser conferidos à sua origem geográfica.

- Indicação de Procedência: alude ao nome do local que se tornou notório por produzir, extrair ou fabricar algum produto ou oferecer determinado serviço.

Para a apreciação dos resultados a serem debatidos, posteriormente, cabe apresentar os registros concedidos aos produtos relacionados à gastronomia (considerando-se apenas os de âmbito nacional, foco da presente pesquisa), até o mês de maio de 2017. Primeiramente, destacam-se os 'selos' de Denominação de Origem, imputados aos seguintes locais e produtos, conforme Quadro 01. 


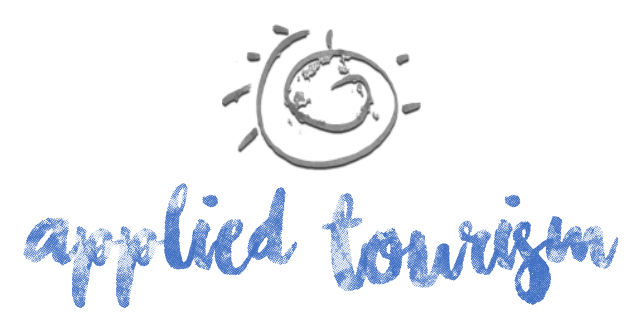

Volume 2, número 3, 2017, p. 01-25

Quadro 1: indicações geográficas - denominações de origem

\begin{tabular}{|c|c|c|}
\hline Estado & $\begin{array}{l}\text { N Indicação Geográfica/ } \\
\text { Nome Geográfico }\end{array}$ & Produtos/Serviços \\
\hline RS & $\begin{array}{l}\text { IG200801 } \\
\text { Litoral norte gaúcho }\end{array}$ & Arroz \\
\hline CE & $\begin{array}{c}\text { IG200907 } \\
\text { Costa Negra }\end{array}$ & Camarões \\
\hline$A L$ & $\begin{array}{c}\text { IG201101 } \\
\text { Manguezais de Alagoas }\end{array}$ & $\begin{array}{l}\text { Própolis vermelha e extrato de própolis } \\
\text { vermelha }\end{array}$ \\
\hline RS & $\begin{array}{l}\text { IG201008 } \\
\text { Vale dos Vinhedos }\end{array}$ & Vinhos: tinto, branco e espumante. \\
\hline MG & $\begin{array}{c}\text { IG201011 } \\
\text { Região do Cerrado Mineiro }\end{array}$ & $\begin{array}{c}\text { Café verde em grão e café industrializado } \\
\text { torrado em grão ou moído. }\end{array}$ \\
\hline PR & $\begin{array}{l}\text { BR412013000002-0 } \\
\text { Ortigueira }\end{array}$ & Mel de abelha \\
\hline MG & $\begin{array}{c}\text { BR412013000005-0 } \\
\text { Vale do Própolis Verde de } \\
\text { Minas Gerais }\end{array}$ & Própolis Verde \\
\hline
\end{tabular}

Fonte: elaborado pelas autoras (2017) com base em INPI (2017).

Em complementaridade ao que foi exposto, o Quadro 02 apresenta as Indicações de Procedência concedidas, aos produtos gastronômicos, até o mês de maio de 2017. 


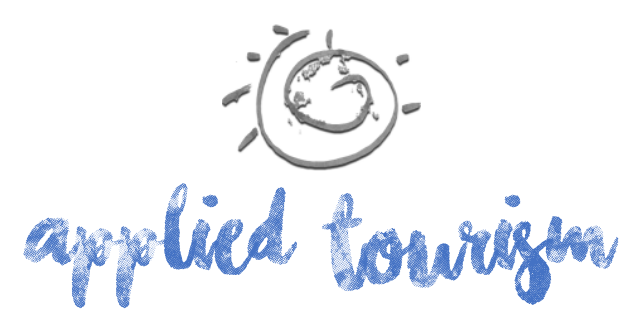

Volume 2, número 3, 2017, p. 01-25

Quadro 2: indicações geográficas - indicações de procedência

\begin{tabular}{|c|c|c|}
\hline Estado & $\begin{array}{l}\text { N Indicação Geográfica } \\
\text { Nome Geográfico }\end{array}$ & Produtos/Serviços \\
\hline RS & $\begin{array}{c}\text { IG200002 } \\
\text { Vale dos Vinhedos }\end{array}$ & Vinhos: tinto, branco e espumante. \\
\hline MG & $\begin{array}{c}\text { IG990001 } \\
\text { Região do Cerrado Mineiro } \\
\end{array}$ & Café \\
\hline RS & $\begin{array}{c}\text { IG200501 } \\
\text { Pampa Gaúcho da Campanha } \\
\text { Meridional }\end{array}$ & Carnes bovinas/ Derivados. \\
\hline RJ & $\begin{array}{c}\text { IG200602 } \\
\text { Paraty }\end{array}$ & $\begin{array}{l}\text { Aguardentes, tipo cachaça e aguardente } \\
\text { composta azulada. }\end{array}$ \\
\hline NE & $\begin{array}{c}\text { IG200701 } \\
\text { Vale do Submédio São } \\
\text { Francisco }\end{array}$ & Uvas de Mesa e Manga. \\
\hline RS & $\begin{array}{c}\text { IG200803 } \\
\text { Pinto Bandeira } \\
\end{array}$ & Vinhos: tinto, brancos e espumantes \\
\hline MG & $\begin{array}{c}\text { IG200704 } \\
\text { Região da Serra da } \\
\text { Mantiqueira de Minas Gerais }\end{array}$ & Café \\
\hline RS & $\begin{array}{c}\text { IG200901 } \\
\text { Pelotas }\end{array}$ & Doces finos tradicionais e de confeitaria \\
\hline ES & $\begin{array}{l}\text { IG201003 } \\
\text { Goiabeiras } \\
\end{array}$ & Panelas de barro \\
\hline MG & $\begin{array}{l}\text { IG201001 } \\
\text { Serro }\end{array}$ & Queijo \\
\hline ES & $\begin{array}{l}\text { IG200909 } \\
\text { Linhares }\end{array}$ & Cacau em amêndoas \\
\hline MG & $\begin{array}{r}\text { IG201002 } \\
\text { Canastra } \\
\end{array}$ & Queijo \\
\hline SC & $\begin{array}{c}\text { IG201009 } \\
\text { Vales da Uva Goethe }\end{array}$ & Vinhos da uva Goethe \\
\hline MG & $\begin{array}{c}\text { IG200908 } \\
\text { Região de Salinas } \\
\end{array}$ & Aguardente de cana tipo cachaça \\
\hline RS & $\begin{array}{l}\text { BR402012000002-0 } \\
\text { Altos Montes }\end{array}$ & Vinhos e espumantes \\
\hline MG & $\begin{array}{c}201104 \\
\text { São Tiago } \\
\end{array}$ & Biscoitos \\
\hline SP & $\begin{array}{c}\text { IG200703 } \\
\text { Alta Mogiana. }\end{array}$ & Café \\
\hline RN & $\begin{array}{c}\text { IG201108 } \\
\text { Mossoró }\end{array}$ & Melão \\
\hline RS & $\begin{array}{c}\text { BR402012000006-3 } \\
\text { Monte Belo }\end{array}$ & Vinhos \\
\hline $\mathrm{Pl}$ & $\begin{array}{l}\text { BR402012000004-7 } \\
\text { Piauí }\end{array}$ & Cajuína \\
\hline BA & $\begin{array}{c}\text { BR402012000001-2 } \\
\text { Microrregião de Abaíra }\end{array}$ & Aguardente de cana tipo cachaça \\
\hline
\end{tabular}




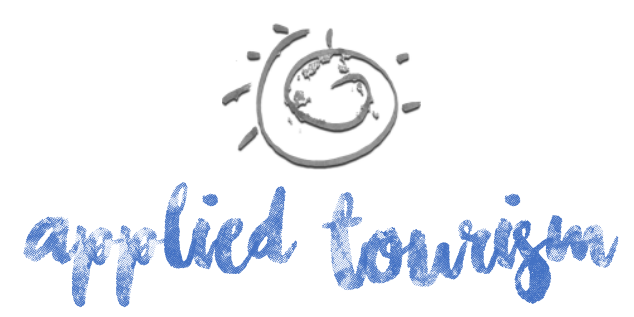

Volume 2, número 3, 2017, p. 01-25

\begin{tabular}{|c|c|c|}
\hline MS/MT & $\begin{array}{c}\text { BR2013000004-0 } \\
\text { Pantanal }\end{array}$ & Mel \\
\hline RS & $\begin{array}{c}\text { BR402014000006-9 } \\
\text { Farroupilha }\end{array}$ & Vinhos brancos, espumantes e brandys. \\
\hline MS & $\begin{array}{c}\text { BR402014000007-7 } \\
\text { Maracaju }\end{array}$ & Linguiça \\
\hline GO & $\begin{array}{c}\text { BR402013000006-6 } \\
\text { Mara Rosa }\end{array}$ & Ação \\
\hline PR & $\begin{array}{c}\text { BR402015000008-8 } \\
\text { Carlópolis }\end{array}$ & Café Verde e Café Torrado e Moído \\
\hline SP & $\begin{array}{c}\text { BR402014000001-8 } \\
\text { Região de Pinhal }\end{array}$ & Inhame \\
\hline ES & $\begin{array}{c}\text { BR402014000004-2 } \\
\text { Região São Bento de Urânia }\end{array}$ & $\begin{array}{c}\text { Café Verde em grão e Café industrializado } \\
\text { Torrado e Moído }\end{array}$ \\
\hline PR & Norte Pioneiro do Paraná & T \\
\hline
\end{tabular}

Fonte: elaborado pelas autoras (2017) com base em INPI (2017).

A Indicação Geográfica, quando utilizada pelos fornecedores, delimita a área de produção restringindo, assim, seu uso aos produtores da região (em geral, reunidos em entidades representativas), mantendo os padrões locais, e impedindo que outras pessoas utilizem o nome desta em produtos ou serviços indevidamente. A IG não tem prazo de validade, por conseguinte, o interesse nacional por esta certificação se mostra cada vez mais significativo (Inpi, 2017), conforme se apresenta nos Quadros 01 e 02.

Nesta conjuntura, origina-se um procedimento de valorização de certos produtos por meio da IG, implicando, deste modo, um vínculo de qualidade, reputação ou outros atributos do produto que podem ser conferidos essencialmente à região produtora (Reis, 2008).

De tal modo, é importante lembrar que é fundamentalmente através da promoção do reconhecimento das qualidades e valores ligados aos produtos locais (qualidades inerentes ao território, aos insumos, ao conhecimento empregado na sua produção, bem como, a sua relevância para a comunidade produtora), que se permitirá à sociedade o conhecimento da história por trás do produto, outorgando visibilidade aos elementos culturais e sociais correspondentes ao mesmo (Krucken, 2001; Krucken, 2009; Bertozzi, 1995; Calliari, Chamas, Bainain, Salles-Filho \& Silveira, 2007; Velloso, 2008). 


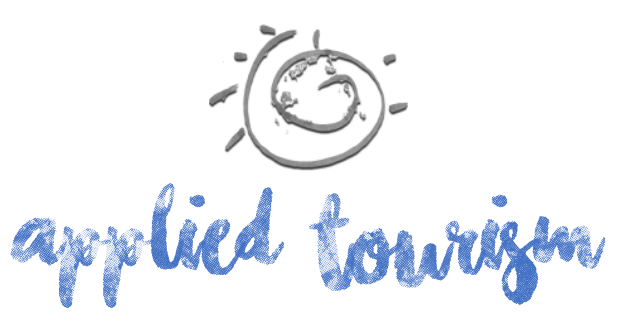

Volume 2, número 3, 2017, p. 01-25

Em tal contexto, surge o Marketing Territorial que, de acordo com Tadini Júnior (p. 40, 2007), se caracteriza como:

[...] a análise, planificação, execução e controle de processos concebidos pelos atores de um território, de modo harmônico e institucionalizado, que tenta, por um lado, dar respostas às necessidades e expectativas dos cidadãos e entidades locais e, por outro, melhorar a qualidade e a competitividade global da cidade no seu ambiente concorrencial.

Em tal contexto, D’Alexandria (2015) aponta que o marketing territorial, em sua essência, busca enaltecer as características do território enquanto mercado, com o objetivo de evidenciar as singularidades que possam ser atrativas para o mercado como um todo. Desse modo, tal conjuntura pode ser trabalhada no contexto das indicações geográficas, pois quando um determinado signo passa a ser reconhecido e o consumidor passa a valorizá-lo, o mesmo adquire um valor diferenciado no mercado. Tal significação associa-se, primordialmente, à confiança que o consumidor deposita naquele que elaborou o produto ou serviço (Bruch \& Areas, 2011).

Sendo assim, torna-se primordial que haja uma comunicação efetiva sobre tal viés, partindo, sobretudo, das esferas públicas e governamentais, pois como aborda Dias (2005), a divulgação e a promoção dos territórios, bem como, das regiões consideradas turísticas, é uma das funções mais relevantes da administração pública, devido seu papel coordenador e unificador de diversas atividades, produtos e serviços ofertados, sendo eles, ligados ou não ao turismo.

\section{PROCEDIMENTOS METODOLÓGICOS}

Ao que se refere à metodologia de pesquisa empregada no presente trabalho, foram utilizadas como base as pesquisas bibliográfica e documental. Considerando-se que a última abrangeu como foco central a análise dos sites governamentais pertencentes às prefeituras dos municípios, bem como, os dos governos dos estados e secretarias de turismo, onde há produto gastronômico contemplado por registro de Indicação Geográfica, através do INPI, seja ela de Indicação de Procedência ou de Denominação de Origem. 


\section{(6) apyplied towrigen}

Volume 2, número 3, 2017, p. 01-25

\begin{tabular}{|c|c|c|c|c|c|}
\hline & $\begin{array}{l}\text { Indicação } \\
\text { Geográfica }\end{array}$ & $\begin{array}{l}\text { Site } \\
\text { próprio }\end{array}$ & $\begin{array}{l}\text { Menções em } \\
\text { Sites } \\
\text { (Municipais/ } \\
\text { Estaduais) } \\
\end{array}$ & $\begin{array}{c}\text { Menções em Sites } \\
\text { de Turismo } \\
\text { (Secretarias/ } \\
\text { Institutos) }\end{array}$ & $\begin{array}{l}\text { Redes } \\
\text { Sociais }\end{array}$ \\
\hline \multirow{7}{*}{ 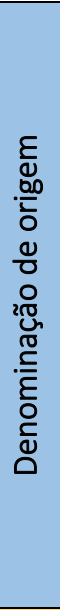 } & $\begin{array}{c}\text { Arroz - Litoral Norte } \\
\text { Gaúcho }\end{array}$ & $x$ & & & \\
\hline & $\begin{array}{c}\text { Camarões - Costa } \\
\text { Negra }\end{array}$ & & & & \\
\hline & $\begin{array}{c}\text { Própolis Vermelha - } \\
\text { Manguezais de } \\
\text { Alagoas }\end{array}$ & & & & \\
\hline & $\begin{array}{c}\text { Vinhos - Vale dos } \\
\text { Vinhedos }\end{array}$ & $x$ & & $x$ & $x$ \\
\hline & $\begin{array}{l}\text { Café - Região do } \\
\text { Cerrado Mineiro }\end{array}$ & $x$ & & & $x$ \\
\hline & Mel - Ortigueira & $x$ & $x$ & & \\
\hline & $\begin{array}{c}\text { Própolis Verde - } \\
\text { Minas Gerais }\end{array}$ & & & & \\
\hline \multirow{18}{*}{ 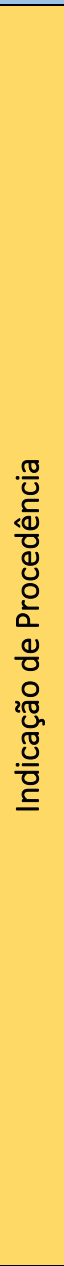 } & $\begin{array}{c}\text { Vinhos - Vale dos } \\
\text { Vinhedos }\end{array}$ & $x$ & & $x$ & $x$ \\
\hline & $\begin{array}{l}\text { Café - Região do } \\
\text { Cerrado Mineiro }\end{array}$ & $x$ & & & $x$ \\
\hline & $\begin{array}{c}\text { Carnes - Pampa } \\
\text { Gaúcho }\end{array}$ & $x$ & & & \\
\hline & Cachaça - Paraty & & $x$ & & \\
\hline & $\begin{array}{l}\text { Uvas e Manga - } \\
\text { Vale do Submédio } \\
\text { São Francisco. }\end{array}$ & & & & \\
\hline & $\begin{array}{c}\text { Vinhos - Pinto } \\
\text { Bandeira }\end{array}$ & $x$ & & & $x$ \\
\hline & $\begin{array}{c}\text { Café - Serra da } \\
\text { Mantiqueira }\end{array}$ & $x$ & & & $x$ \\
\hline & Doces - Pelotas & $x$ & & & $x$ \\
\hline & $\begin{array}{c}\text { Panelas de barro- } \\
\text { Goiabeiras }\end{array}$ & $x$ & & & $x$ \\
\hline & Queijo - Serro & & & & \\
\hline & Cacau - Linhares & & $x$ & & \\
\hline & Queijo - Canastra & & & & $\mathrm{x}$ \\
\hline & $\begin{array}{c}\text { Vinhos - Vales da } \\
\text { Uva Goethe }\end{array}$ & $x$ & & & $x$ \\
\hline & Cachaça - Salinas & $x$ & & & \\
\hline & $\begin{array}{c}\text { Vinhos - Altos } \\
\text { Montes }\end{array}$ & $x$ & & & $x$ \\
\hline & $\begin{array}{c}\text { Biscoitos - São } \\
\text { Tiago }\end{array}$ & & & & \\
\hline & Café - Alta Mogiana & $\mathrm{x}$ & & & $\mathrm{x}$ \\
\hline & Melão - Mossoró & & & & \\
\hline
\end{tabular}




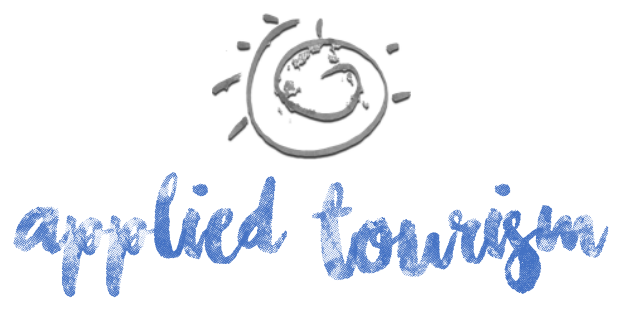

Volume 2, número 3, 2017, p. 01-25

\begin{tabular}{|c|c|c|c|c|c|}
\hline $\begin{array}{c}\text { Vinhos - Monte } \\
\text { Belo }\end{array}$ & $X$ & $X$ & & \\
\hline Cajuína - Piauí & & & & \\
\hline Cachaça - Abaíra & & & & $X$ \\
\hline Mel - Pantanal & & & & \\
\hline $\begin{array}{c}\text { Vinhos - } \\
\text { Farroupilha }\end{array}$ & $X$ & & & \\
\hline $\begin{array}{c}\text { Linguiça - Maracaju } \\
\text { Açafrão - Mara } \\
\text { Rosa }\end{array}$ & & & & \\
\hline Goiaba - Carlópolis & $X$ & & & \\
\hline Café - Pinhal & & & & \\
\hline $\begin{array}{c}\text { Inhame - São Bento } \\
\text { de Urânia }\end{array}$ & & & & \\
\hline $\begin{array}{c}\text { Café - Norte } \\
\text { Pioneiro do PR }\end{array}$ & & & & \\
\hline
\end{tabular}

Fonte: elaborado pelas autoras (2017).

Observou-se que cerca de 42\% das indicações geográficas analisadas não possuem nem um tipo de 'divulgação' sendo realizada. Não há menções em sites públicos (municípios/estados), nem em domínios próprios ou redes sociais. O que é, de certa forma, um contrassenso com o esforço que representa o alcance de uma indicação geográfica, a qual ocorre por meio de um processo complexo, com uma vasta reunião de documentação e que exige um esforço considerável. Além de que, como observou Reis (2008), mencionado anteriormente, origina-se um procedimento de valorização de certos produtos por meio das IGs, sugerindo, assim, um vínculo de qualidade, reputação ou outros atributos do produto que podem ser conferidos essencialmente à região produtora. O que poderia ser utilizado como uma potente ferramenta de divulgação local, podendo ser convertido em um diferencial, uma forma de valorização do território e, até mesmo, um produto turístico.

Deve-se salientar que, além das IGs que não possuem nenhum tipo de divulgação, apenas 14\% destas são divulgadas pelos sites dos seus respectivos municípios e estados, e $6 \%$ pelas respectivas secretarias e institutos de turismo. Apesar de, em alguns casos, possuírem logomarcas, sites e até mesmo páginas em redes sociais, as IGs geralmente não são apresentadas a quem acessa as páginas públicas da região/localidade a qual elas pertencem. 


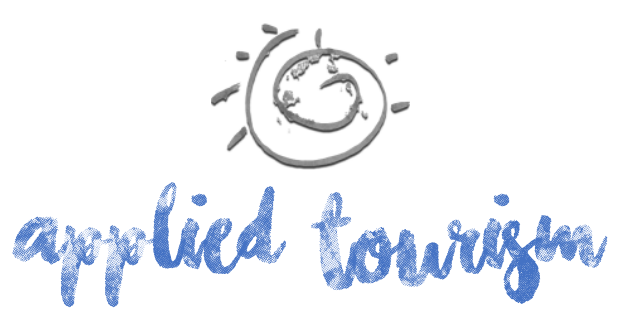

Volume 2, número 3, 2017, p. 01-25

Outro ponto interessante verificado durante as análises foi que em aproximadamente 70\% dos casos, as IGs que possuem sites próprios, também, estão presentes nas redes sociais, demonstrando um grande interesse em se aproximar dos consumidores, levar os seus produtos até o mercado por canais diversificados, comumente, exaltando a qualidade e a possibilidade de rastreabilidade dos produtos adquiridos. Sendo que, estes sites e páginas em redes sociais, são geralmente geridos por associações/cooperativas de produtores dos produtos certificados.

Desta forma, nota-se certa falta de diálogo entre o poder público e estas cooperativas/associações produtoras, para a realização de um trabalho conjunto, aumentando as possibilidades de alcance da divulgação dos produtos/serviços com indicações geográficas concedidas. Pois, conforme mencionado anteriormente, é essencialmente através da promoção e do reconhecimento das qualidades e valores ligados aos produtos locais (qualidades inerentes ao território, aos insumos, ao conhecimento empregado na sua produção, bem como, a sua relevância para a comunidade produtora), que se permitirá a sociedade o conhecimento da história por trás do produto, concedendo visibilidade aos elementos culturais e sociais intrínsecos ao mesmo (Krucken, 2001; Krucken, 2009; Bertozzi, 1995; Calliari et al, 2007; Velloso, 2008).

Logo, contribuirá de maneira concreta para o desenvolvimento de uma imagem apropriada do território em que o produto é gerado, promovendo amparo ao patrimônio cultural, à adoção e valorização de métodos de sustentabilidade na produção, na comercialização e até mesmo no consumo (Glass \& Castro, 2008; Krucken, 2009; Bowen \& Zapata, 2009).

Ainda deve-se destacar uma importante observação acerca de algumas IGs específicas: elas são/possuem relação com patrimônios tombados pelo IPHAN (Instituto do Patrimônio Histórico e Artístico Nacional). Nomeadamente, as panelas de barro de Goiabeiras, o queijo da Serra da Canastra e a Cajuína do Piauí. E, em relação a isso, observou-se uma divulgação considerável destes tombamentos realizados pelo IPHAN nas páginas observadas, contrapondo-se à escassez de informações sobre as certificações obtidas por meio das IGs. 


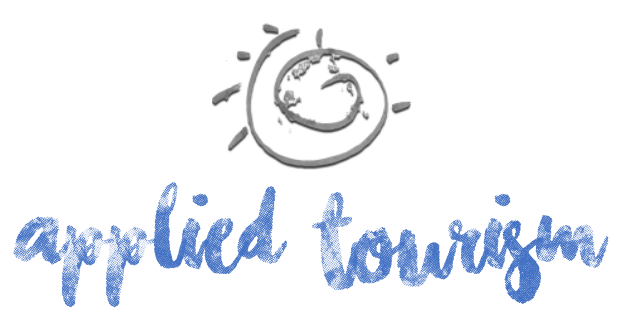

Volume 2, número 3, 2017, p. 01-25

desenvolvendo produtos e serviços com fortes associações simbólicas e emocionais, utilizando-se das facilidades fornecidas pelos registros de IGs. Pois, a diversidade de percepções e pontos de vista dos atores envolvidos na produção e no consumo pode constituir uma fonte enriquecedora para a renovação. Isto, por meio de ações que visem promover produtos e territórios, de maneira coletiva e distribuída, ações estas que podem ser verificadas a seguir.

Figura 4: ações do design para a comunicação de produtos locais.

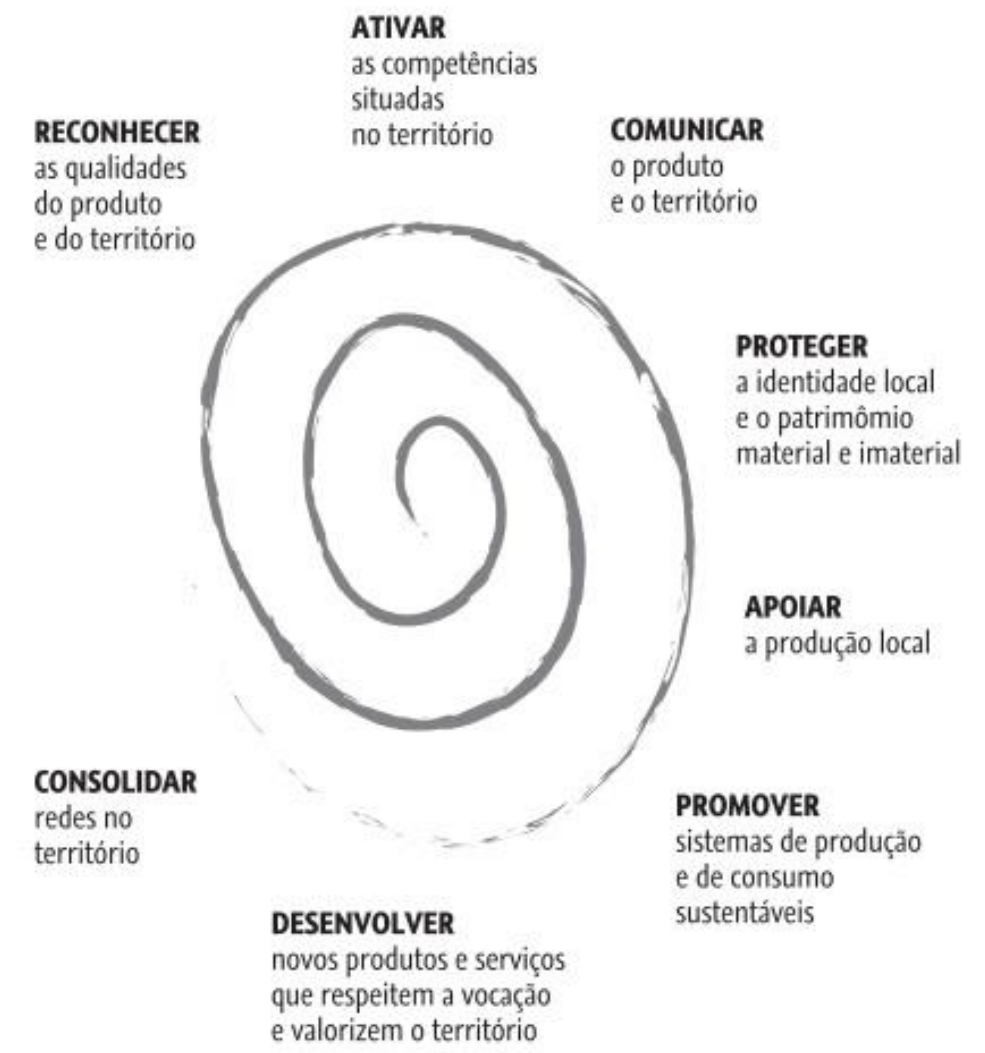

Fonte: elaborado pelas autoras (2017) com base em Krucken (2009).

A partir do que foi exposto e das ações discutidas na Figura 04, pode-se afirmar que o poder da publicidade e os meios de comunicação para a construção de uma imagem não devem ser menosprezados, porque muitos consumidores podem rapidamente captar a ideia de um espaço específico e determinar se esta é a mensagem que é transmitida pela propaganda 


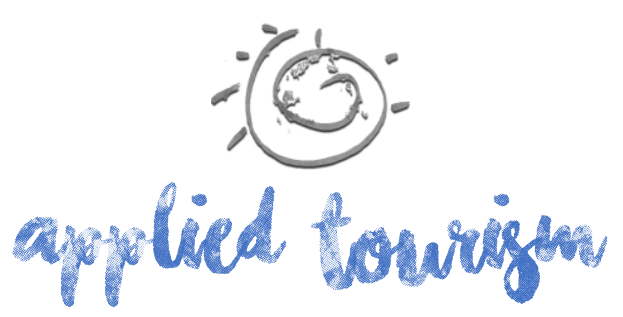

Volume 2, número 3, 2017, p. 01-25

(Barjolle ET AL, 1998), devendo-se levar em consideração todos os pontos discutidos por Krucken (2009) em sua figura, pois com essas ações os produtos locais podem passar a ser comunicados de maneira contundente e os territórios a serem mais valorizados.

Desta forma, a relevância desta pesquisa funda-se no fato de que as marcas territoriais, as indicações geográficas e toda a correlação que existe entre o território e esses conceitos, que poderiam funcionar como uma ferramenta estratégica para a promoção de desenvolvimento dos próprios territórios -, estão sendo negligenciados, prejudicando um potencial de trazer dimensões significativas para estes territórios e os produtos que os comunicam. Logo, sugere-se a realização de estudos mais aprofundados sobre a utilização das IGs como um elemento de diferenciação e valorização de produtos, bem como, a promoção de iniciativas que despertem no poder público e nas associações/entidades relacionadas às IGs no Brasil o interesse por difundi-las e valorizá-las, permitindo assim, uma maior disseminação deste conceito, a fim de 'educar' consumidores e produtores a respeito de sua importância e toda a carga de cultura, conhecimento, originalidade e complexidade que representam.

\section{REFERÊNCIAS}

Aurier P., Fort F. \& Sirieix L. (2005). Exploring terroir product $m$ earnings for the consumer. Anthropology of food, 2005.

Barjolle, D., Boisseau, S. \& Dufour, M. (1998). Le Lien au Terroir: Bilan de Travaux de Recherche. Institut d'Economie Rurale. Antenne Romande, Lausanne, Switzerland.

Bérard L. \& Marchenay P. (2004). Les Produits de Terroir: Entre Cultures et Règlements. CNRS Editions: Paris.

Bérard L. \& Marchenay P. (2007). Produits de Terroir: Comprendre et agir. França: Centre National de la recherche scientifique.

Bertozzi, L. (1995). Designations of origin: quality and specification. Food Quality and Preferences. (06): 03, 143-147.

Biz, A. A \& Ceretta, F. (2008). Modelo de gerenciamento do fluxo de informação dos portais turísticos governamentais uma abordagem teórica. Revista Turismo Visão e Ação. (10): 03 , $399-414$. 


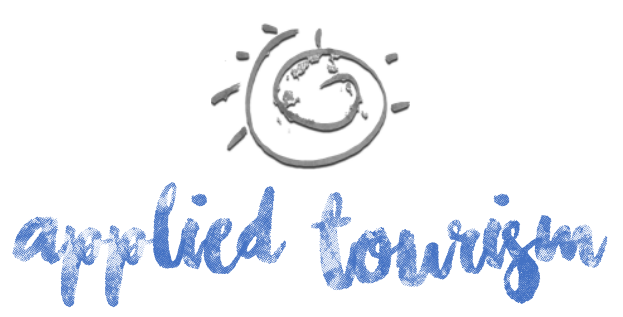

Volume 2, número 3, 2017, p. 01-25

Colóquio Hispano-Portugués de Estudios Rurales: La Multifuncionalidad de los Espacios Rurales de la Península Ibérica. Anais... IV; Santiago de Compostela.

Trigueiro, C. M. (1999). Marketing \& Turismo: como planejar e administrar o marketing turístico para uma localidade. Rio de Janeiro: Qualitymark.

Valente, M. E. R.; Perez, R.; Ramos, A. M. \& Chaves, J. B. P. (2012). Indicação geográfica de alimentos e bebidas no Brasil e na União Europeia. Ciência Rural. (42): 03, 551-558.

Vargas, I. C. S. (2008). Indicações geográficas do Brasil: possibilidades para os produtores inseridos na área de proteção ambiental do Ibirapuitã- RS. Dissertação (Mestrado em Extensão Rural). Centro de Ciências Rurais, Universidade Federal de Santa Maria, Rio Grande do Sul.

Velloso, C. Q. (2008). Indicação geográfica e desenvolvimento territorial sustentável: a atuação dos atores sociais nas dinâmicas de desenvolvimento territorial a partir da ligação do produto ao território (um estudo de caso em Urussanga, SC). Dissertação (Mestrado em Agroecossistemas). Centro de Ciências Agrárias, Universidade Federal de Santa Catarina, Santa Catarina.

Velloso, C. Q. V.; Bruch, K. L.; Cadori, A. A. \& Locatelli, L. (2010). Identificação dos produtos potenciais e organização dos produtores. In: Cerdan, C. M. et al. (Org.). Curso de propriedade intelectual \& inovação no agronegócio: Módulo II, indicação geográfica. 2. Ed. Brasília: MAPA, Florianópolis: SEaD/ UFSC/ FAPEU, 94-129.

Von Dentz, B. G. Z. (2017). A produção artesanal de comida tradicional como patrimônio imaterial: perspectivas e possibilidades. Revista RIVAR. (04): 11, 92-116. 